\title{
EMPLOYEE PERCEPTION OF STRATEGIC HRM PRACTICES IN SMES OF MANUFACTURING SECTOR IN INDIA - A STUDY
}

\author{
${ }^{1}$ Shaji Kurian \& ${ }^{2}$ Dr. G.P. Naik
}

\begin{abstract}
Global competitive nature of business, forced even the small scale industries in India to be highly dynamic and competitive, forcing the Indian companies to make a introspective thinking, to assess their strengths and weaknesses against that of the global players.

Increasing competition, locally and globally, call for organizations to be more adaptable, resilient, agile, and customer-focused to succeed. In this scenario, Human Resource aspects in Small and Medium Enterprises requires a different focus altogether. Many previous studies on small businesses rank HRM practices as the second most important management activity next to general management. But do SMEs give due importance in aligning HR with SME strategy?

Small Scale Industries (SSI) is one of the significant segments of the Indian economy, contributing about 9 per cent to the Indian GDP and providing employment to over 65 million people and its success. Human Resource Management (HRM) coupled with innovation are key parameters in development of an individual as well as of an organization. Now the challenges of organization is basically about integration and adaptations and that is the core of strategic Human resource Management (SHRM).

There can be several reasons of dissatisfaction with pay, HR policies and practices, lack of hygiene factors, employee loyalty issues, and the like. Therefore these strategic HR issues in SMEs are analysed in this paper. This paper highlights the internal challenge to business owners and entrepreneurs and encourages to focus their vision to be propelied by clearly defined goals which are communicated to their teams.
\end{abstract}

\section{INTRODUCTION}

When big organizations go on a rampage, small ones have to think smart. This is the wisdom for India's small and medium enterprises (SMEs) that fail to keep pace with the growth juggernaut. Amidst lot of competition within SMEs, it becomes very important for the SMEs to benchmark various processes in order to remain competitive within the marketplace and ensure they can benefit from what their competitors are doing to stay one step ahead of the game. Human resources are one of the most essential growth indicators for these organizations.

\section{${ }^{1}$ Mr. Shaji Kurian}

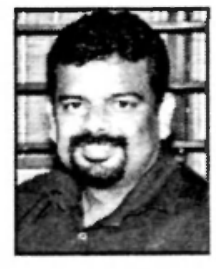

Assistant Professor.

IFIM Business School. \# 8P \& 9P

KIADB Industrial Area. Electronics City,

Phase 1. Bangalore - 560100

E-mail : shaj_kurian@yahoo.com

Tel : 9742316960 (O) 080-41432878

www.ifimbschool.com
As a result, global competitive nature of business, the business game have changed and the business environment has become highly dynamic and competitive, forcing the Indian companies to make a introspective thinking, to assess their strengths and weaknesses against that of the global players and go in for formulating strategies to make their strength and weaknesses pruned to favourably utilize the changing external environment.

Importance of SSIs in India

SSI is one of the significant segments of the Indian economy, contributing about 9 per cent to the Indian

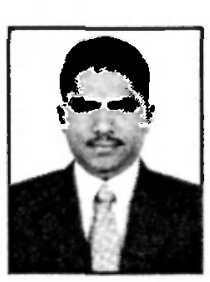

${ }^{2}$ Dr. G.P. Naik

Professor,

B.N.M Institute of Technology

12th Main Road, 27th Cross.

Banashankari 2nd Stage.

Bangalore - 560070

Tel : 91-80-26711781 
GDP and providing employment to over 65 million people. The Indian SME segment's current production value is almost $R s 880805$ crore. It contributes to around $45 \%$ of industrial production \& exports. It manufactures more than 9,000 diverse products, ranging from low-tech items to technologically-advanced products. The SSI sector targets both domestic as well global markets. SSlssector is recognized as the engine of growth, accounting for about $70 \%$ of employment and contributes a significant amount for the growth of GDP. Globally, 99.7 per cent of all enterprises in the world are SME's and the balance 0.3 per cent is large-scale enterprises. By contrast, the SSI sector in India accounts for 95 per cent of all industrial units.

Table 1:Performance and growth trend of MSME Sector in India.

\begin{tabular}{|l|l|l|l|l|l|l|}
\hline SI.No. & $\begin{array}{l}\text { Year } \\
\text { MSMEs }\end{array}$ & $\begin{array}{l}\text { Total } \\
\text { Investment } \\
\text { (lakh } \\
\text { numbers) }\end{array}$ & $\begin{array}{l}\text { Fixed } \\
\text { (Rs. Crore) }\end{array}$ & $\begin{array}{l}\text { Production } \\
\text { (lakh person) }\end{array}$ & $\begin{array}{l}\text { Employment } \\
\text { (Rs. Crore) }\end{array}$ & Exports \\
\hline 1 & $2000-01$ & 101.1 & 146845 & 261297 & 238.73 & 69797 \\
\hline 2 & $2001-02$ & 105.21 & 154349 & 282270 & 249.33 & 71244 \\
\hline At 2001-02 prices & & 162317 & 314850 & 260.21 & 86013 \\
\hline 3 & $2002-03$ & 109.49 & 170219 & 364547 & 271.42 & 97644 \\
\hline 4 & $2003-04$ & 113.95 & 178699 & 429796 & 282.57 & 124417 \\
\hline 5 & $2004-05$ & 118.59 & 188113 & 497842 & 294.91 & 150242 \\
\hline 6 & $2005-06$ & 123.42 & 500758 & 709398 & 594.61 & 182538 \\
\hline 7 & $2006-07$ & 261.01 & 558190 & 790759 & 626.34 & 202017 \\
\hline 8 & $2007-08$ & 272.79 & 621753 & 880805 & 659.35 & 214143 \\
\hline 9 & $2008-09$ & 285.16 & & & & \\
\hline 50 & & & & & & \\
\hline
\end{tabular}

Source: MSME Report 2010

The industry groups with a large share in exports are hosiery and garments (29.0\%), food products (21.4\%) and, leather products $(18 \%)$. The SSI units continue to create employment. The number of employed in the SSI sector went up from 626.34lakh in 2007-08 to 626.34lakh in 2008-09. This sector is next only to agriculture in employment. 


\section{Graph 1: Employment Growth}

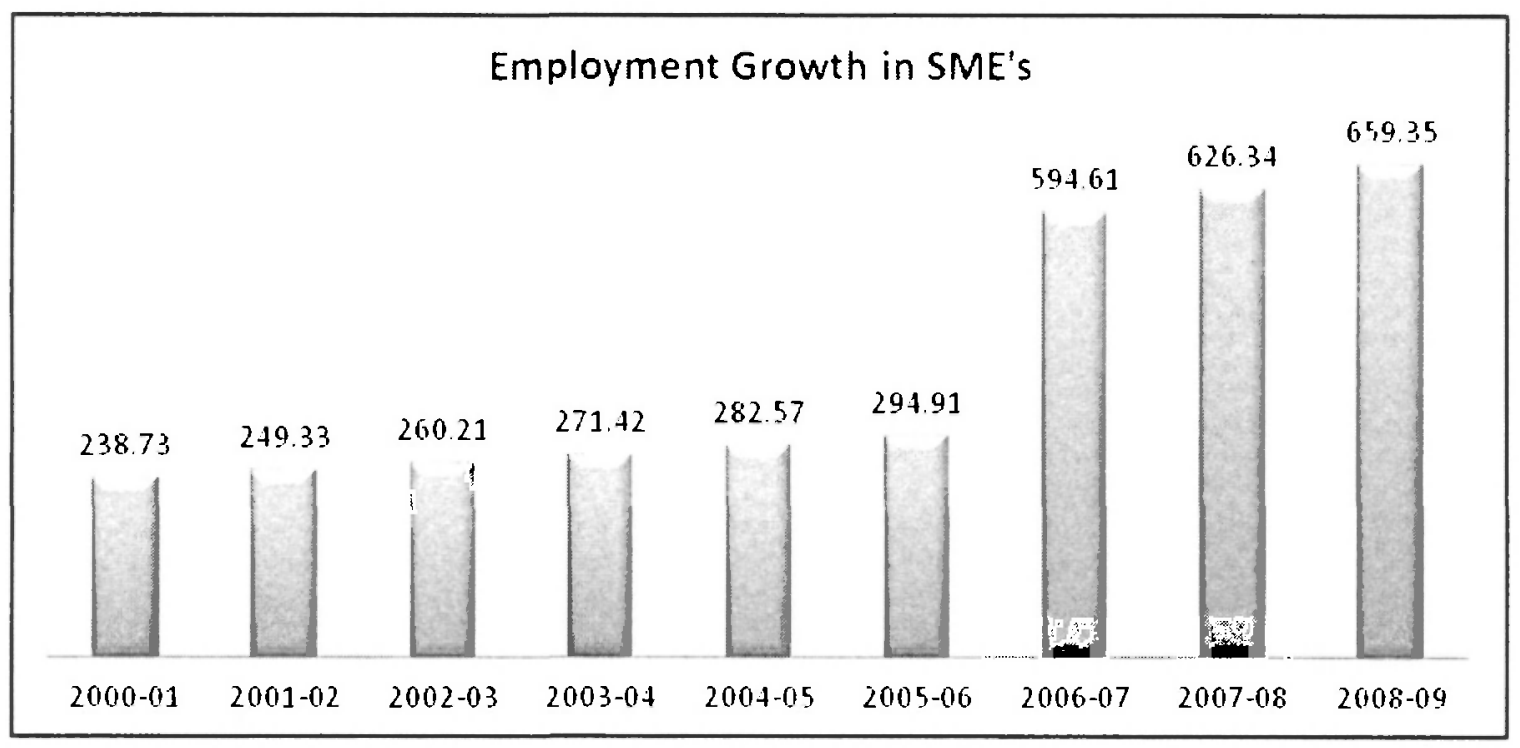

Source: MSME Report 2010

The fixed investment grew by 5.04 per cent from Rs. 558190 crore in 2007-08 to Rs. 621753 crore in 2008-09. About 8.000 products are manufactured in the small-scale sector. The production of SSI units in India increased from Rs. 790759crore in 2007-08 to Rs. 880805 crore in 2008-09. The industry groups-with a large share in the total production of SSIs such as textile products, wood. furniture, paper, printing. and metal products-have recorded high growth rates. The exports grew at a faster rate than production in 2002-03. While production at current prices grew by about 10.53 per cent and exports rose by 20.7 per cent from Rs. 202017 crore to Rs. 214143 crore between 2007-08 and 2008-09.

Graph-2: Investment, Production and Export

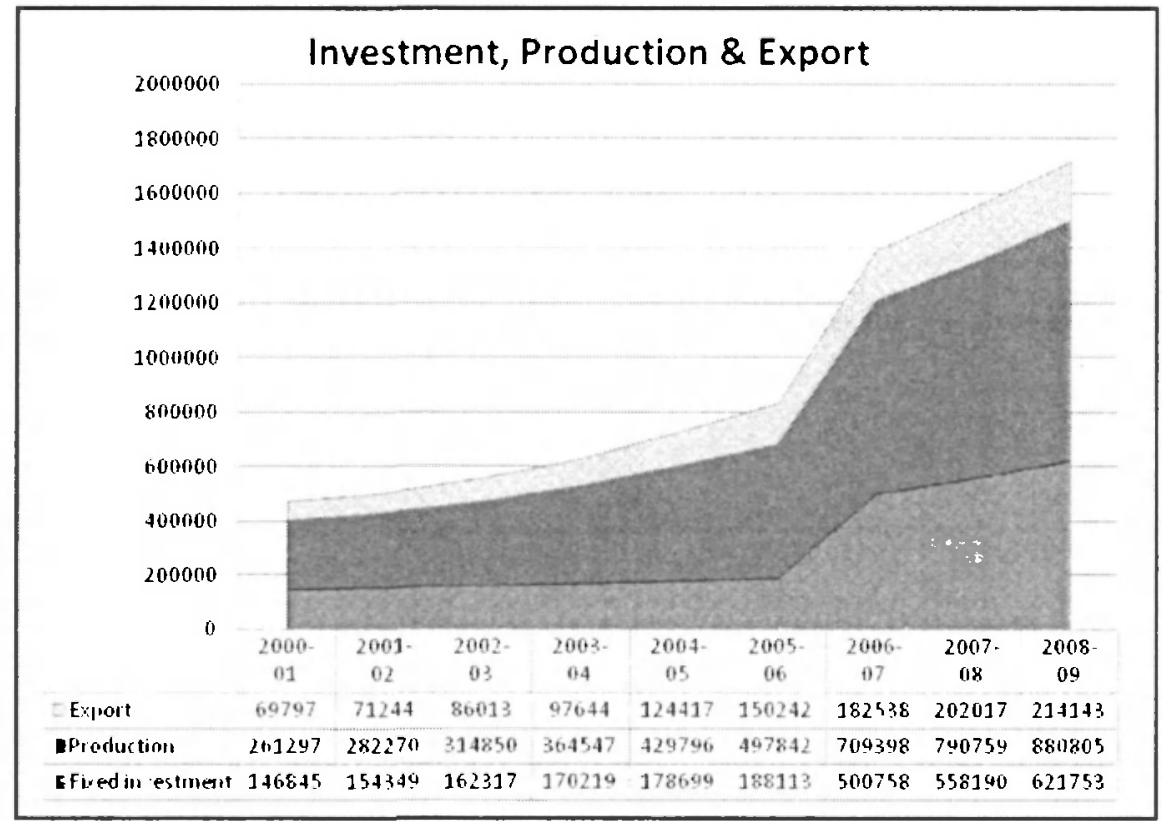

Source: MSME Report 2010 
According to the Ministry of Small Scale Industries, the number of registered SSI units in India has increased from 27.2 million units in 2007-08 to 28.5 million units in 2008-09, up 3.6 per cent.

Graph - 3: Growth in number of MSMEs

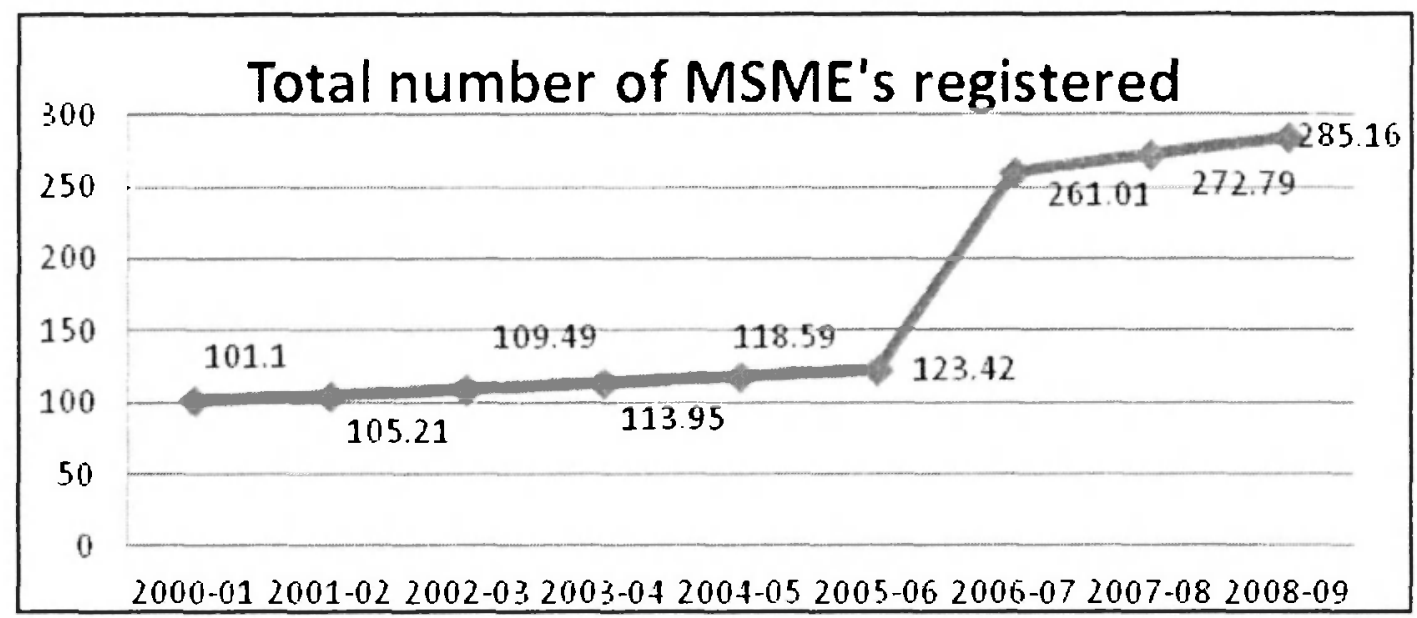

Source: MSME Report 2010

\section{RATIONALE FOR THE STUDY}

Human Resource Management (HRM) coupled with innovation are key parameters in development of an individual as well as of an organization. Managing human resources effectively has become vital to organizations of the $21^{\text {st }}$ Century in view of the emerging global competitiveness of organizations. Now the challenges of organization is basically about integration and adaptations and that is the core of strategic Human resource Management (SHRM).

The lack of "in place and streamlined" HR functions in these organizations come as a weakness when all the efforts invested in building a team become fruitless because of high attrition rates. There can be several reasons to this such as dissatisfaction with pay, HR policies and practices, lack of hygiene factors. employee loyalty issues, and the like. Therefore these strategic HR issues in SMEs are analysed in this paper.

The SMEs are facing unforeseen competition operating under the liberalized environment. The dynamic nature of organization development calls for a periodic review of systems of HRM, its climate and training and development programs. It is also important to study how an organization is responding to global competition through innovative SHRM practices.

\section{RESEARCH METHODOLOGY}

At the outset, this study was meant for exploring the Strategic issues in Human resource Management of SMEs and therefore we have a two fold source of information, a primary research basically among the business heads and other key functional heads and employees. And the secondary research to explore the level of HR practices in SMEs in recent years. Convenient sampling technique was used for data collection. The questionnaire was administered among 105 respondents from SME sector in the state of Karnataka. Respondents are employees of middle management cadre.

\section{Analysis and Interpretation}

Questionnaire was constructed to assess the extend to which various HR function are performed in SME organizations. The first part of questionnaire focused on respondents generic perception about overall growth indicators of SMEs.

Thereafter the questionnaire was subdivided into
A) HRM as an Integrative function in the respective companies
B) Strategic Relevance of HRM with respect to their companies

C) HR practices in Recruitment function 
D) HRM \& Training

E) HRM practices in Appraisal function

F) Role of HRM in Reward and Compensation Based on the survey data was compiled and analysed.

\section{DATA ANALYSIS}

Following tables depict the graphical representation about the respondents perception regarding key HRM indicators.

In the first table we have analysed the respondents generic perception about overall growth indicators of SMEs. The key performance indicators surveyed were productivity, growth, profitability, market share, Financial stability, and focus on innovation in SME segment.

\section{Graph 4: Respondents generic perception of organisation}

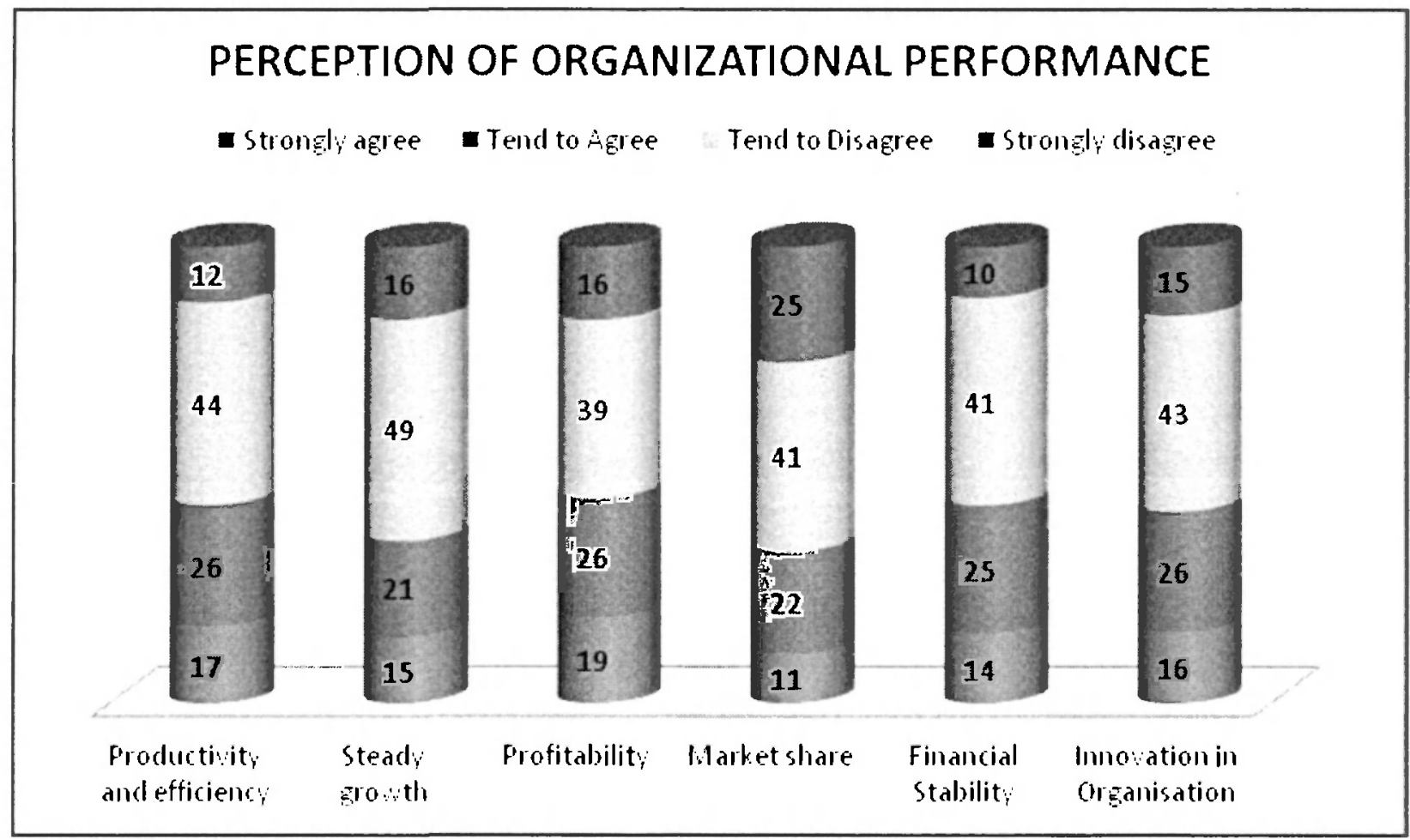

Interpretation

According to the table, if we merge together strongly agree and tend to agree groups together it falls below $50 \%$. It indicates that in most of the organisaions, employees perception or factual intepretation about their own organisation with regards to the above parameters are not very exciting. More than $50 \%$ of the respondets have a pessimistic view of the performance indicators. 
EVALUATION OF OTHER HUMAN RESOURCE MANAGEMENT PRACTICES-

Graphs 5: Role of HRM as an Integrative Factor

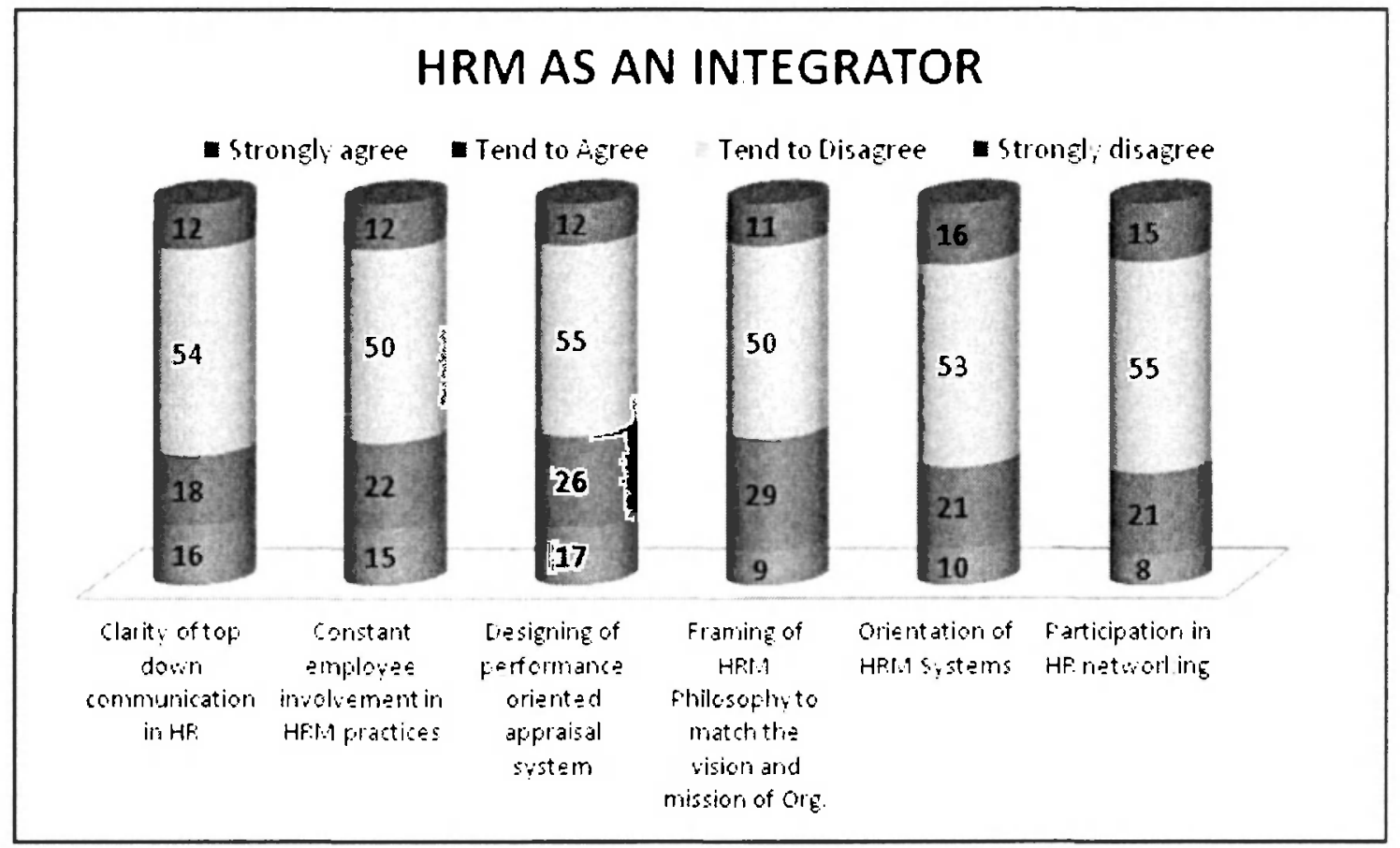

According to the graph, most of the employees do not perceive the role of different HRM functions as a key integrator in most of the organizations.

Graph 6: Perceived Strategic Relevance of HR

\section{STRATEGIC RELEVANCE OF HR}

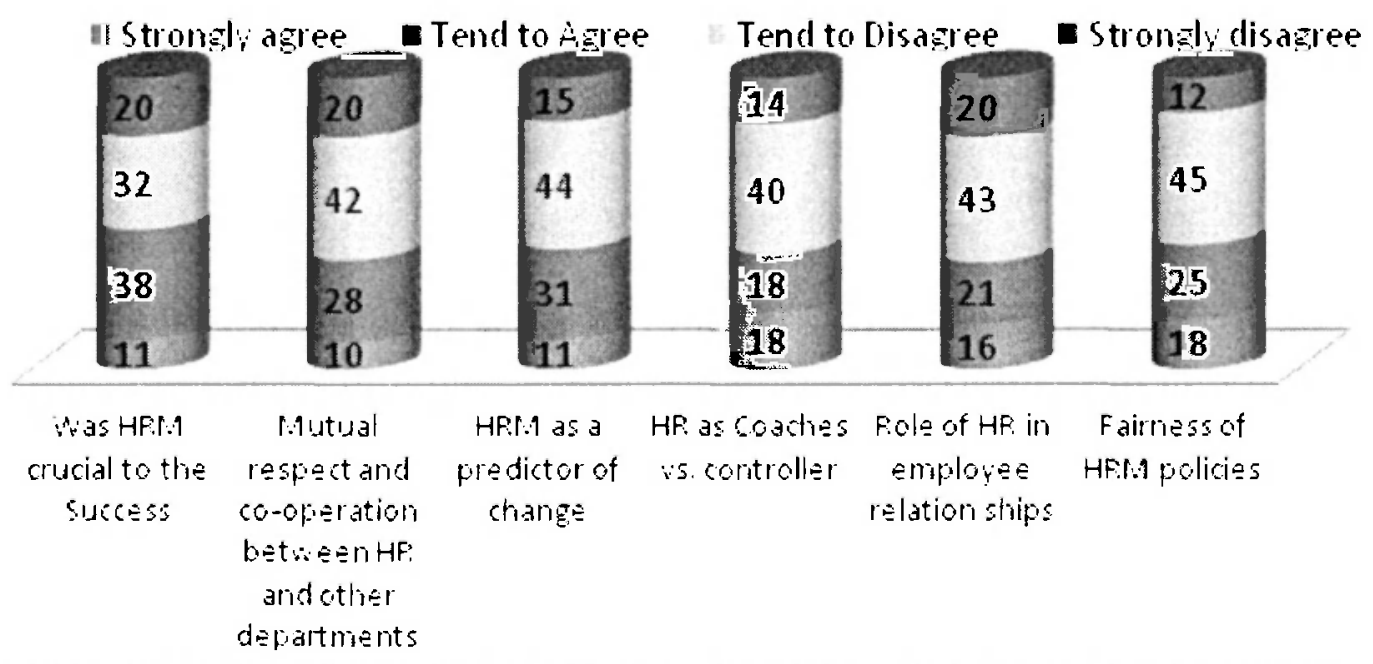




\section{RECRUITMENT FUNCTIONS}

- Strongly agree - Tend to Ágree Tend to [risagree a Strongly disagree
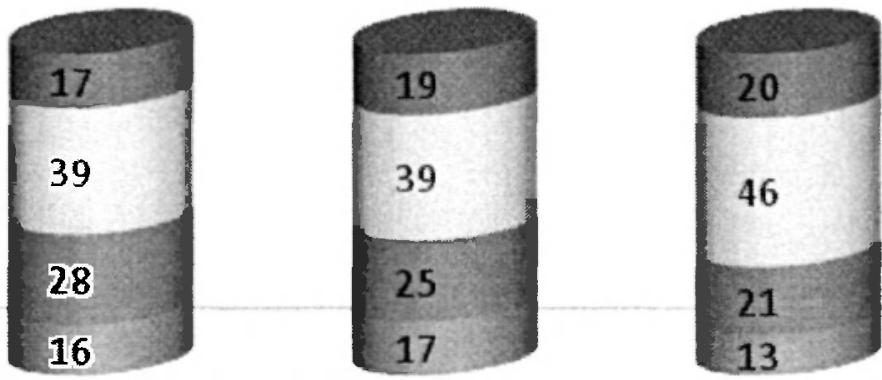

Pecruitment of cualified people for

managerial position
Intemal information dissemination of job requirements
Existence of formal induction program

(1)

Graph 8 - HRM Practices -Evaluation of Training Function

\section{HRM \& TRAINING}

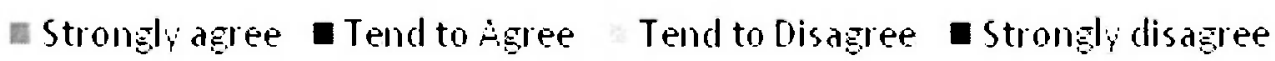

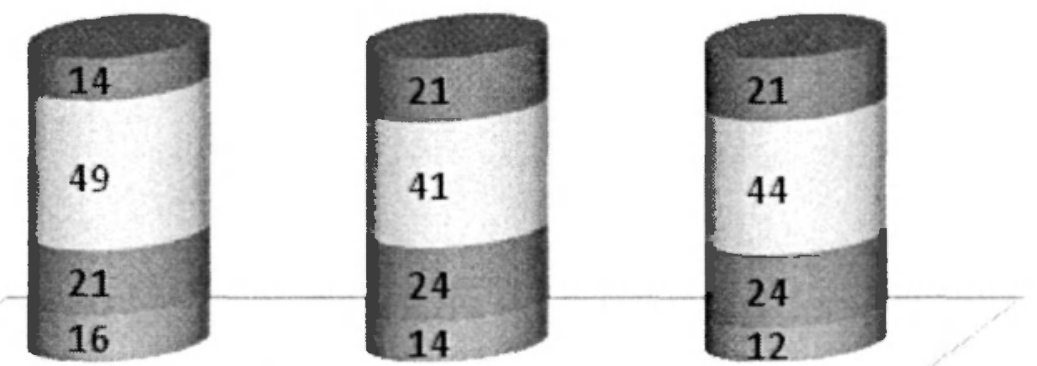

Scope of applicationtraining to practice
In:ol:ement of limemanager as coach
Crossfunctional learning: 


\section{APPRAISAL SYSTEM}

Etrongly agree $\mathbf{m}$ Tend to Agree Tend to Disagree $\mathbf{n}$ Strongly disagree

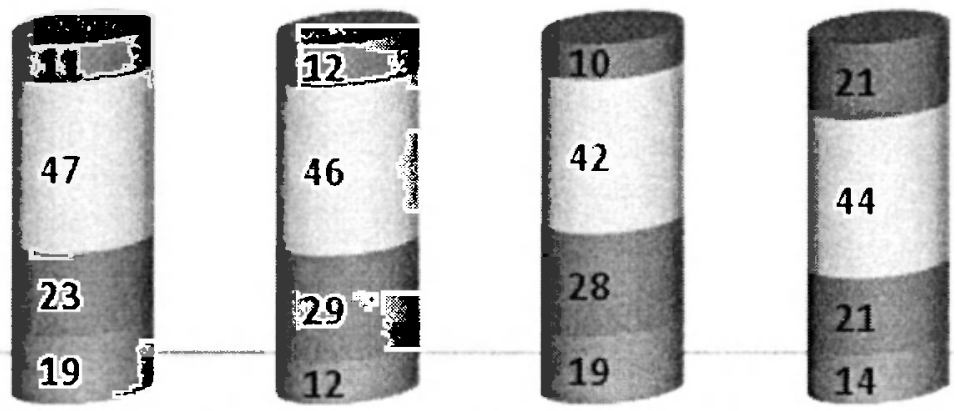

\begin{tabular}{|c|c|c|}
\hline $\begin{array}{c}\text { Provisicifor an } \\
\text { appeal }\end{array}$ & $\begin{array}{l}\text { Importance of } \\
\text { peopile } \\
\text { management as } \\
\text { parameter }\end{array}$ & $\begin{array}{l}\text { Transparency of } \\
\text { implement ation }\end{array}$ \\
\hline
\end{tabular}

Graph 10: HRM Practices - Rewards

\section{REWARDS AND COMPENSATION}

w Strongly agree Tend to Agree Tend to Disagree strongly disagree

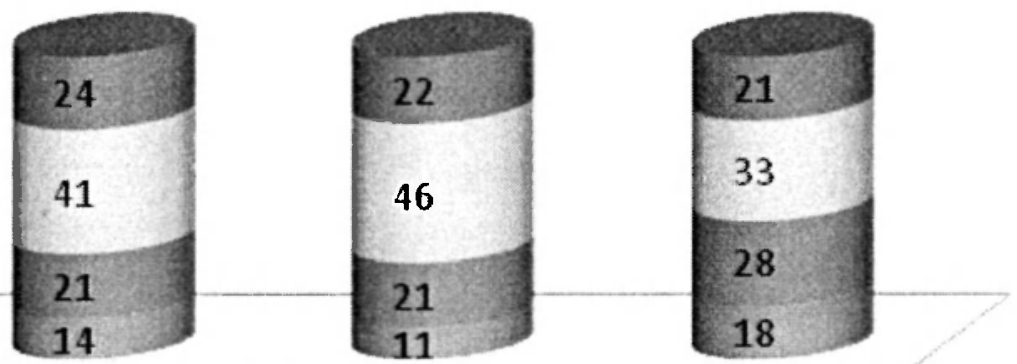

Flexible working Performance

Clear hours linked rewards communication of reward policy 
Following table indicates the structural differences in HR activities of SMEs

Table 2: HR structure and practices in SME

\begin{tabular}{|l|l|l|}
\hline HR-Responsible & Explicit Strategy and policy in HR & Employment conditions fixed through \\
\hline Accountant & Few or None & Bargaining \\
\hline Chief accountant & Some & Bargaining \\
\hline Managing Director & Many & Owner/CEO \\
\hline HR Manager & Some & Owner/bargaining \\
\hline Manager (Production) & Some & Bargaining \\
\hline Owner & Some & Owner/Bargaining \\
\hline
\end{tabular}

Interpretation

The first findings of the survey indicate that diversity exists, in as much as different types of employees and managers are handling the HR-issues. Secondly there seems to be status differences across the SMEs when it comes to HR practices. Based on the status of the person who handles the HRM functions, strategies and policies of HRM as well as employment conditions changes.

These two finding support the argument, that a universalistic approach to HRM is not fruitful. A situational or a configurational approach seems to produce more understanding.

\section{ATTENTIONREQUIRED}

Based on the study: some of the areas where support required and not limited in Indian context are:

Focus on Workforce competency: One of the key areas of neglect in SME is the recruiting appropriate manpower and further retaining it. Most SMEs manage human resource on a lose basis, giving up on a chance for organisational development and performance. Fostering entrepreneurship through the informal mode that is - user friendly, uncomplicated and efficient is important in the Indian SME scenario.

Technology Up gradation: Growing from micro to small or medium to big needs an open mind to invest in accessible technology. Preparedness to reinvent processes and methods needs to be facilitated through government initiatives to increase availability of latest technology in various segments.

Induction with right training: Bringing in the convenience of IT is still resisted by SMEs to leverage their development process. Holding them back are:

- Affordability and to a large extent, prioritising knowledge tools

- Training for utilising business processes

- Acceptance of the need for education and training contributing to the task environment and general environment. 
Widening outlook: As India Inc grows, those Indian SMEs that are forward looking and prepared to adapt to changing environment, will have plenty of opportunities. Bringing about a modification of mindset in the entrepreneurs in the sector and encouraging optimum utilization of human and economic resources are essential. Also important is updating the SMEs with global developments to give a direction to skill development will empower the sector for the benefit of all.

\section{CONCLUSION}

SMEs in India are either family run businesses or run by first generation entrepreneurs who may not have the backing of collateral or family assets. An entrepreneur today needs to play the role of the effective leader who forges confidently toward the future and emerges with a high performance organization.

The internal challenge to business owners and entrepreneurs is the development of people who manage the business and drive the organization. The focus of their vision has to be propelled by clearly defined goals which are communicated to their teams.

\section{RESEARCH LIMITATIONS AND IMPLICATIONS OF THE STUDY}

Since the study was focused to generally to a particular area, random sampling technique was used. It might not have given us the accurate picture. Some of the issues discussed in the questionnaire must have been analysed subjectively by the employees. However, it provides a strong base to further research in co-relating respondents perceptual base with actual performance indicators.

\section{REFERENCES:}

Annual Report on MSMEs, 2009-10, Ministry of MSME Govt. of India.

Delbridge, R., Kenney, M. and Lowe, J. (1998) 'UK Manufacturing in the Twenty-First Century: Learning Factories and Knowledge Workers?' in Manufacturing in Transition, Delbridge, R. and Lowe, J. (Eds), Routledge, London.

Khalid Nadvi., Hubert Schmitz (1999) 'Industrial Clusters in Less Developed Countries : Review of experiences and Research agenda', Discussion paper, 339, Institute of Development Studies.

www.smechamberofindia.com

www.imtma.in 